\title{
Material Engagement Theory and Sustainability: The materiality of social change
}

\author{
Peter Graham \\ Concordia University
}

\begin{abstract}
Material Engagement Theory (MET) is a recent theoretical development in the field of cognitive archaeology. It represents an important new tool for sustainability theorists. MET overcomes the Cartesian conceptual separation of mind and matter, providing important insights into the cognitive nature of human-environment relations. If we recognize that we think with and through material tools and environments and not just about them, what does that mean for sustainability policy and social change theory? The example of a naturalized garden in a Canadian suburban community is used to illustrate what MET can do for sustainable development theory.
\end{abstract}

\section{INTRODUCTION}

This paper provides a brief description of Material Engagement Theory (MET), an explanation of MET's potential for sustainability and social-change theorizing, an example of MET applied to a specific case study within a Canadian suburban context, and a concluding discussion of what MET might offer us to improve our understandings and modellings of sustainability and social change in future. The main advantage of MET as a theoretical model for sustainability and social-change theory is that it provides a very accessible, and therefore sharable and institutionalize-able, pathway to a post-Cartesian, (relational) ontology. Western societies must first overcome the inherent deceptions and delusions of the Western historical inheritance - the mediational means traceable to the era of European Enlightenment when the compulsion to dominate became a shared modus vivendi representative of an entirely unsustainable way of becoming with the world.

\section{WHAT IS MATERIAL ENGAGEMENT THEORY?}

The development of Material Engagement Theory (MET) represents an important breakthrough in the interdisciplinary understanding of what a mind is and what a mind does. The foreshadowing promise of a fully developed MET was first presented in the 2004 collection of essays edited by Demarrais, Gosden, and Renfrew and published under the title Rethinking materiality: the engagement of mind with the material world. Malafouris further developed these ideas, distilling them into a sort of handbook of MET, titled How Things Shape the Mind: A Theory of Material Engagement (2013). Malafouris gathered together the enabling foundational prerequisites for MET rom earlier writings by authors from many different research traditions whose focus was roughly the role of materiality within human cognition and sociocultural development. MET emerged from within Malafouris's home field of cognitive archaeology 
by borrowing from and building on several previously independent lines of tangential scholarly inquiry, including, for example, the works of Gregory Bateson (1972), sociocultural analysis (Cole, 1996; Vygotsky, 1978, 1986; Wertsch, 1991, 1998) phenomenology (Heidegger, 1971, 1977; Merleau-Ponty, 1962; Tilley, 1991, 1994, 1999), cognitive science (Clark, 1997, 2003; Gibson, 1979; Hutchins, 1995), and anthropology/material culture (Appadurai, 1986; Bennett, 2010; Ingold, 2007; Miller, 2005, 2008, 2010). MET also emerged partly as the culmination of efforts over more than one generation of archaeology scholars working to answer the "sapient paradox" (Renfrew, 2001, 2009), that is, the question of how and why the modern human emerged from earlier hominids. The convincing argument that engagement theory and, later, MET put forward to answer that question has been essentially that it was cognitive engagement with novel material tools (stone hand axes) within communities of practice (Lave \& Wenger, 1991) that changed human developmental processes and thereby also changing the evolutionary context. This change in evolutionary context came about primarily with the making and use of flaked stone tools (Ingold, 2013) within cooperative learning environments (peripheral participation), followed by a widespread shift from nomadism to sedentism during the Neolithic (Renfrew, 2009). These engagement processes occurred over extremely long time periods resulting in the gradual establishment of a vastly more complex material culture and a radically transformed cognitive environmental context (Boivin, 2008; Knappett, 2004). The contemporary human is little changed genetically since the time of the Neolithic, but cognitively contemporary humans are almost unrecognizable as being related to the first Homo sapiens. What has changed, and what distinguishes the modern human from the Neolithic human, is a very different historical inheritance of material culture and mediational means - a transformed and transforming already-lived-in-world, in other words.

When sustainability is framed as a problem of the embodied, situated, extended, distributed, enacted, mediated, and dynamical mind, as explained by Malafouris (2013), new and important understandings of (un-) sustainability can be achieved. Instead of looking for solutions to the sustainability challenge in either the information-deficit-afflicted brain or the mismanaged environment, MET, like phenomenology (e.g., Smith, 2011; Stefanovic, 2001), opens the possibility of escaping this false dichotomy and locating the genesis of unsustainability within an ecology of mind distributed across amalgamations of person, mediational means, and environment, combined within shared practices of human action. MET, borrowing from developmental psychology, makes the point that there is never just a brain. Brains are always embodied. They are always embedded within a cultural context. They are always extended into environment and that (cultural) environment always extends also into the brain, causing some synapses to fire and others to atrophy, resulting in a temporally and geographically specific body/brain/environment constellation or "ecology of mind" to use the Batesonian term. As Malafouris (2013) states, "Human thinking is, first and above all, thinking through, with and about things, bodies, and others" (p. 77; italics in original). Persons are always perceptually, cognitively and emotionally situated by their relations with cultural tools and environments. That character of being situated is reflected in the mediational means transmitted from one generation to the next as part of a historical inheritance including, for example, language, myths, metaphors, and frames, but also cultural and ecological materiality, like village squares, super markets, computer screensavers, iPhones, tree plantations, and even real forests or, in other words, forests whose voice people listen to and respect.

Malafouris (2015) states: "We create things that very often alter the ecology of our minds, reconfigure the boundaries of our thinking and the ways we make sense of the world" (p. 351). As the complexity of our material engagements has increased, from say flaked stone tools, cooking fires, and clay pots to iPhones, nanoparticles, and assassination drones, (to mention only a few), our mediated cognitive processes have also come to reflect and come into correspondence with a changed material universe, and vice versa. This change should be a troubling development for anyone concerned with sustainability, not to mention those charged with the maintenance of society's psychological health (Malafouris, 2013; Gifford \& Gifford, 2016; Turkle, 2011; Väliahho, 2014).

The things we create very often represent the materialization of a dominant underlying ideology indexical of a specific historical context, as is the case with the rise of the screen based "visual economy." Väliahho (2014) explains: "One way to conceptualize these continuous propagations and exchanges 
between images, bodies, and technological platforms is to model them as 'visual economies' in the classic sense of 'economy' as the management of realities" (p. 92). The "biopolitical apparatus" (Väliahho, 2014), in other words, becomes a mediational means within the person/cultural tool/environment triad that works to foreclose sustainability. Our world, or human umwelt, then becomes for us something programmable or toggle-able as we spend more time in that kind of world. We come to see ourselves in consequence as always acting upon as opposed to being with our world. There is always tacit knowledge embedded in the materiality we engage with and when that tacit knowledge reflects a Cartesian dualistic perspective, we should not be surprised when unsustainability is the inevitable outcome.

It would be wrong to see the problem, however, simply in such linear terms. Although ideologies and other mediational means sometimes drive the design of material artifacts, material artifacts and environments also drive the evolution of ideologies and other mediational means. Think for example of the words being added to dictionaries every year, or think of how the automobile or the laptop computer have transformed our sense of community. Lawnmowers, antibacterial soaps, or clothing fashions work similarly to reconstitute our identities and our ways of becoming in a dynamic world. Agency, in other words, should be conceptualized as something that is distributed and travels across the various elements of extended minds in all directions. The lesson for sustainability theorists is that when mind is theorized as being extended across brains, bodies, cultural tools, and environments, then all these variables must be included in our representational models of sustainability or anything else we design and put into the world (see also Fry, 2012). This reconceptualization of distributed agency has important implications for how social changes occur and what any road map to sustainability might look like.

Often the things we create, whether material tools or cultural landscapes, do not represent - they are not symbols that can be deciphered and read like a text (Boivin, 2008) and we should be careful not to overlook this caveat. Things we engage with form integral parts of an "ecology of mind" (Bateson, 1972) and as such integral parts of our shared psychological developmental processes as well. From the MET perspective, we are very much with the world, in the sense of always being engaged in reflexive coconstitutive processes. Parts of the world we are in active engagement with are sometimes experienced as a world and not simply as a representation or index of something else. The world in this way educates our mind (both individually and collectively), establishing affordances and constraints, providing the underlying basis and supporting foundations for the tacit metaphors and other cultural-cognitive tools that give structure and texture to our perceptual, emotional and cognitive schemata, for better or worse.

The Enlightenment has bequeathed a specific set of cultural tools that has been mastered by, but also has mastered, Western peoples and societies in ways that prioritize the cognitive over the material, the human over the non-human, the cerebral over the corporeal, and so on. MET works to rebalance our understanding of ourselves in a world that is increasingly configured into alignment with the misguidance of those Enlightenment-generated cultural tools. The result of Cartesian mediational means is, in general, a form of induced delusion. Discounting the agency of human and non-human others and things situates our perceptions, thoughts, and emotions at odds with a readily observable world. This contradiction between the dictates of the already-lived-in world, filled with cultural tools and tacit knowledges we are born into and our experience of being in that world imparts a schizophrenic characteristic to Western culture (Bateson, 1972). On the one hand, our cultural tools teach us to believe and behave as if we believe that we can destroy environment without destroying ourselves. On the other hand, the consequences and the implicit stories of putting those tools into practice are everywhere only too apparent, taking such forms as an overcarbonized atmosphere, an overplasticized biosphere, overly consumptive cultural norms or an overly atomistic noosphere (Boulding, 1978) to provide just a few examples.

The human mind generally works incessantly to put the world, however presented, into a narrative form. These narratives do not necessarily require words or language. The computer screen establishes a relationship with its user that requires no text, the characteristics of that relationship escape and are not entirely expressible using verbal description, and yet the ongoing story-like relationship is no less real for being tacit. As we think through our technologies, we generally fail to notice that agency is also being distributed to and exercised by the technologized object or thing. The Western story-the story of 
mastering and civilizing, in other words - is more about obfuscation, forgetting, wasting, and obliterating than it is about the actual achievement of even the most modest capacities to escape the various voices and agencies of the world. Within the Cartesian gestalt we become less free, not more, although our awareness of our slavery may be lessened. From the Cartesian perspective, we see ourselves operating on the world, but fail to notice the world, as we have configured it, also operating on us. The recent and dramatic rise in "social distress" (Gifford \& Gifford, 2016) is one example of our general underestimation of the level of neurosis being transmitted through Cartesian cultural tools, not only from generation to generation, but also into such materializations as mowed lawns, supply-demand models, plastics, nanoparticles, mine tailings, greenhouse gas emissions (GHGs), and so on and then travelling back in loops to our own cognitive processes (Hird, 2017). These materializations also set the parameters of our constructed reality, determining which stories can be told and which cannot. Sustainability is being systematically written out of the script by our physical and cultural environments as much as by our mediated social selves, and perhaps what has the least say of all in these antidemocratic processes is our brain-bodies.

\section{SUSTAINABILITY, MEDIATIONAL MEANS AND SOCIAL CHANGE}

The problem of sustainability from the MET perspective becomes a problem of thinking through and together with environment rather than limiting ourselves to simply thinking about a conceptualized as separate environment. It means shifting from acting on the world to becoming co-constitutively with the world. This might begin by simply acknowledging and listening to the many voices of human, nonhuman, living, and inert others rather than conceptualizing those others as unruly and untidy bits of a world in need of guidance and mastery. If we take the famous Bruntland Commission's definition of sustainability as one example, the world we leave for future generations is no longer from the MET perspective just "out there", but rather now needs to also include the mediational means of future minds, as those minds can be situated, extended, and distributed in an increasingly sustainability-configured world. Sustainability, from this expanded perspective, would involve the transmission of cultural tools, both material and conceptual, of sustainability rather than simply a junk pile of economic objects (commodities) that might be put into some sort of liveable configuration through the usual Western practices of domination and mastery. Western-style knowledges are misunderstood as approaching objectivity while ignoring the reflexive and implicit world-directing agency of the tacit aspects of those Western knowledges. The current processes of civilization, processes of transforming our world into plastics, nanoparticles, mine tailings, greenhouse gases, and other forms of human waste, are also part of the package, part of the leavings for future generations, but it is important to recognize that these processes are as much mental as they are physical. The potential for continuing the contemporary Western practices, guided by the contemporary mediational means, is simply running out of room. Latour (2017) asks about this obvious conundrum: "If there is no planet, no earth, no soil, no territory to house the Globe of globalization to which all countries claim to be heading, what should we do? Either we deny the existence of the problem, or we come down to earth. For each of us, the question now becomes, 'Are you going to keep nursing dreams of escape, or are you going to search for a land in which you and your children might live?" (p. 80). The mental and the material cannot be disentangled in the collective enactment of our world.

What then does MET mean for policy developers, community development practitioners, analysts, politicians, educators, journalists, story tellers, and other social change agents? To answer that question, let us think about what social change really entails. Social change means people behaving, interacting, engaging with the world differently. Social change is, in other words, always perceptual/cognitive/emotional but it always also involves a changed mediated material engagement. It cannot be confined to the realm of ideas but rather must have material dimensions. Those material dimensions, however, are also parts of culturally shared material engagement processes, whether beating bobo dolls as in Bandura's experiments (Graham \& Arshad-Ayaz, 2016) or becoming addicted to the screens of personal computing devices (Turkle, 2011; Väliahho, 2014) or demonstrating mastery over 
one's world with an air freshener, lawn mower, or antibacterial soap, or more hopefully, in naturalized gardens, Occupy movements, sustainable design, Transition Towns and other tentative materializations of sustainability. Social change begins with a socially practiced change in material engagement and it spreads through the extended and distributed mind from there. The idea that we must start with a fully formed idea and end with the imposition of that idea onto the world is simply more than incomplete; it is just plain wrong. Just as unthought material engagements with stone tools birthed our species into the world, we will need different forms of material engagements to redirect our extended and distributed minds towards sustainability. To understand social change is to recognize that mind can no longer be conceptualized as something operating between our ears with data collected from a disconnected "environment." Mind instead extends and is distributed across brain, body, cultural tools, and environment with no part of the process being independent of the others.

What might such a social change process look like in practice? The important points we can take from MET are that social change always involves a new mediational means being put into changed communities of practice, but perhaps even more importantly, social change always entails changed material engagement processes. The example of the introduction of a naturalized garden to a Canadian suburban community will now be used to illustrate these points. Here the changed materiality and the new cultural tools or mediational means of sustainability evolve in tandem. Neither the naturalized garden nor the gardener can exist without the embodied, extended, distributed, dynamic material engagement that brings that specific ecology of mind into being.

FIGURE 1

\section{FRONT YARD}

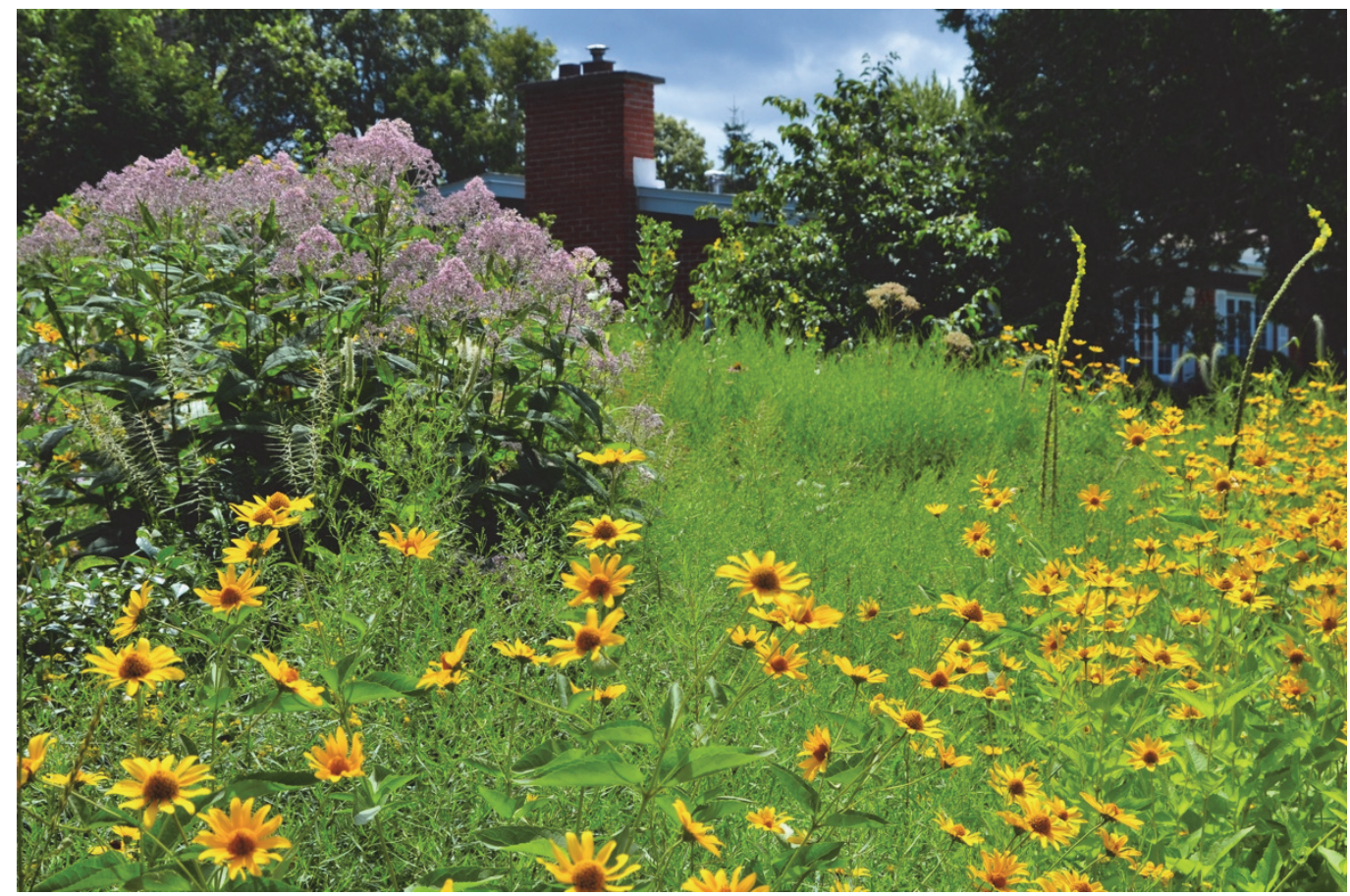

Source: Gary Kennedy 2017

\section{THE NATURALIZED GARDEN}

What is a naturalized garden? From my perspective, a naturalized garden is a garden exercising some degree of agency in a cooperative rather than a confrontational fashion. It is a garden where plants can have some say about where they will grow and birds and other non-human community members can 
participate in the planting and growing (see Figure 1). Suburbanites are more typically conditioned to ritualistically demonstrate mastery over environment through engagements with lawnmowers, weed eaters, leaf blowers, and so on. Naturalized gardens can be recognized by their capacity to constitute the gardener into a cooperative and empathetic naturalized system. That system is constituted by a naturalized gardener, appropriate cultural tools, and the naturalized garden. Such a constellation can be contrasted with a garden that is designed and enacted by a gardener pretending to control the garden. In a mowed lawn system, the gardener becomes the unwitting slave of the garden while pretending to demonstrate mastery (Robbins, 2007). Much like MET, in other words, the naturalized garden represents a model of escape from the Cartesian-mediated social mind.

The garden, mowed lawn, or anything else, of course, never actually operates in the imagined Cartesian manner. Brains, bodies, tools, and environments are not separable in practice. A brain or a body, without a naturalized garden simply becomes a different kind of brain and a different kind of body. Likewise, a naturalized garden cannot be materialized without the naturalized garden brain/body, it also becomes something else. Suburban environments generally are materializations of the mythology of domination: the domination of thought over matter, the domination of human over environment, the domination of market forces over competing interests, and so on. It is that Cartesian mythology coupled with materializations that gives rise to the practice of enacting the suburban environment in the first place.

The knowledges of embodied, extended, and distributed dynamic minds are often tacit knowledges. The agency of the naturalized garden that pushes the human subject towards sustainability may at times be quite subtle, but it is nevertheless relentless. The garden becomes lively as flowers attract pollinators, also drawing the attention of the gardener through that liveliness. That shift in material engagement provides the gardener with a new cognitive tool, one that challenges the master-slave type of humanenvironment relationship characteristic of the Enlightenment inheritance. The liveliness of the garden becomes integral to livelier minds. The garden also implicitly troubles the minds of passersby whose Cartesian mediational means object to the seemingly unmastered and wasted space of the garden. That troubling occurs implicitly, below the level of conscious awareness. People are generally unable to articulate their objections beyond vague protestations over the apparent "messiness" or "untidiness" of the scene. The naturalized garden provides new affordances and constraints - new possible minds. Interactions with the increased biodiversity the naturalized garden affords result in incidental psychological benefits. Opportunities for teaching and learning multiply as the world begins to transform into more than simply an unruly student and into something rather more like a teacher. New metaphors and other cognitive tools become available to structure perceptual, cognitive, and emotional practices. The world becomes friendlier and the human sense of self begins to dribble away into environment. The garden begins to enlist an ally.

To be clear though, these affordances, constraints, and the pull of the garden at the mind of the gardener can also be resisted-the agency of the configuration is always distributed. A native species garden can form the same garden-human dyad as a mowed lawn, depending on the cultural tools used to engage that relationship. The key is really whether the locus of control is conceptualized in one individual part of the system or whether it is seen to be distributed throughout the system. When the native species garden becomes the enactment of a ritual of control, then we will not have gotten very far in our understanding and practice of sustainability and there will not be much social change to talk about. If, in other words, the gardeners imagine themselves as imposing their preformed idea of the native species garden onto a teachable tabula rasa, then the engagement process is not very different from the process of the mowed lawn. The native species can object as much as mowed grasses can, and either can take control of the Cartesian-minded gardener. Material engagement processes, in other words, are never optional. We are always perceptually, cognitively, and emotionally engaged with things in the world, the key is how those engagements are mediated with which cultural tools. This lesson is applicable to any sustainable development or social change problem.

The locus of resistance to sustainability or social change is not technically in the brain of the gardener so much as it is distributed throughout the system. The origin of the resistance is within the Cartesian historical inheritance, but that historical inheritance is not limited to cognitive tools, it includes the 
entirety of the already-lived-in-world. Any historical inheritance is always continuously circulated throughout the brain-body/mediational means/environment triad. The gardens we design with either sustainability or unsustainability minds, become two distinct types of world and each of those two types of world in turn designs two distinct types of peoples.

\section{DISCUSSION}

The lessons from MET applied to a naturalized garden are broadly applicable to sustainable development and social change theory. The first important point we need to make is that the design of a theory, or any other thing that is then put into the world, should be understood as always having an implicit impact on the already-lived-in world, however slight that impact might be. This point is critically important because those things we put into the world always provide implicit orientations, tacit knowledges, within a dynamic ecology of mind. The naturalized garden needs to swim against the tide of adjacent and surrounding Cartesian materializations, but the visceral way in which passersby encounter the naturalized garden does open up the dominant Western body-brain/cultural tool/environment constellation to questioning. When the tacit Western assumption of the rightness of a mind to dominate and control matter is openly violated with the materialization of the natural garden, one is forced to question previously taken for granted assumptions. Even the dynamic nature of the naturalized garden, with different species of flowers continuously cycling through seasons of budding, blooming, and then making and distributing seeds, provides a stark contrast to the neighbouring mowed lawns that seem to be deliberately frozen in time. Theories of sustainability or social change should also be understood to work like a naturalized garden or like a mowed lawn. A good theory, like a good materialization, works to put the loops of becoming with the world into a sustainable practice. Theories that reinforce the primacy of thought over matter work, like the mowed lawn, to reinforce the status quo-unsustainability. Any theory, in other words, that posits rational profit maximizers needing to obtain new and better knowledges to correct deficiencies in either brains or environments, will probably work mainly to reinforce unsustainability over the longer term. Until we begin to take these implicit aspects of our designed theories and things seriously, we will probably not get very far in the direction of sustainability and not really understand the origins or directions implied by any process of social change.

The second lesson we can learn is that changed materializations in themselves do not provide us with a magic bullet to bring about social change in the direction of sustainability. Broad based social change takes time - a luxury we may no longer have. The transformation from one community of thought, say "lawn people", to another, say naturalized garden people may also require some guidance, an organizing narrative or way of making the new practice meaningful. It may also require a means of spreading those cultural tools rapidly to bring more people into the new community of practice. The danger exists, though, that if naturalized gardens became fashionable, if the transmission process occurred too rapidly, then it might be enacted with the old cognitive tools. The naturalized garden, in other words, might become just another commodified aesthetic, marketed by gardening services companies offering the rarest species to be brought under the control of the sovereign consumer. Recycling provides one other clear example of a social change process that has not brought about increased sustainability (Hird, 2017). The set of mediational means that structure the practice of recycling does not deviate from the dominant Western tools of unsustainability. There is no reason to believe that other social changes towards sustainability would not also be susceptible to similar process of being usurped and dissolved into the dominant Western meaning system-plus ça change! The fairy tale story of recycling, far from being a decisive step towards sustainability works to reinforce unsustainability. Nevertheless, the point that changing our relationship with the land necessarily entails changing the way we configure the land cannot be overstated. Changed materializations represent a necessary but insufficient condition of social change. 


\section{CONCLUSION}

What MET tells us about social change is that we can let the material world do much of the hard work of changing minds. It also tells us that ideas on their own, without corresponding materializations, are not the best generators or sustainers of social change. Sustainability taught in the classroom must then be put into a brain-body/cultural tool/environment community of practice for it to become meaningful and durable. The crux of the problem may simply be that the world has been configured into a Cartesian nightmare-Latour's absence of any place to continue the project of globalization. Sustainability materializations simply do not fit in to our Cartesian configured world. The ideologies of unsustainability simply line up with the way things appear to have been configured in the world we are born into. Those materializations make those ideologies seem right. The story of unsustainability is now written in the all too apparent recycling bins, electric cars, and bamboo toothbrushes whispering gently, "You must be insane!" Education for sustainable development (ESD) runs into this problem routinely, but so long as education is limited to the realm of ideas, and fails to affect changes to material culture, we will continue to struggle (and probably continue to fail) to, in the words of Latour "come down to earth."

\section{ACKNOWLEDGEMENTS}

This research would not have been possible without the generous support of the Concordia University Part Time Faculty Association Professional Development Fund (CUPFA), Montreal, Quebec, Canada and the support of the faculty and staff at Loyola College for Diversity and Sustainability at Concordia University, Montreal, Quebec, Canada. Thanks to Dr. Mick Smith, Dr. Graham Whitelaw, and Colin Khan of the School of Environmental Studies, as well as Dr. Rena Upitis of the Faculty of Education, of Queen's University, Kingston, Ontario, Canada. Finally, Teri-Ann McDonald provided invaluable assistance with editing.

\section{REFERENCES}

Appadurai, A. (Ed.) (1986). The social life of things: Commodities in cultural perspective. Cambridge, UK: Cambridge University Press.

Bateson, G. (1972). Steps to an ecology of mind. Chicago, IL: University of Chicago Press.

Bennett, J. (2010). Vibrant Matter: A Political Ecology of Things. Durham, NC: Duke University Press.

Boivin, N. (2008). Material cultures, material minds: The impact of things on human thought, society, and evolution. New York, NY: Cambridge University Press.

Boulding, K. (1978). Ecodynamics: A new theory of social evolution. Beverley Hills, CA: SAGE.

Clark, A. (1997). Being there: Putting brain, body, and world together again. Cambridge, MA: MIT Press.

Clark, A. (2003). Natural born cyborgs: Minds, technologies, and the future of human intelligence. Oxford, UK: Oxford University Press.

Cole, M. (1996). Cultural psychology. Cambridge, MA: Harvard University Press.

DeMarrais, E., Gosden, C., \& Renfrew, C. (Eds.). (2004). Rethinking materiality: The engagement of mind with the material world. Cambridge, UK: McDonald Institute for Archaeological Research.

Fry, T. (2012). Becoming human by design. London, UK: Berg.

Gibson, J. J. (1979). The ecological approach to visual perception. Boston, MA: Houghton Mifflin.

Gifford, E., \& Gifford, R. (2016). The largely unacknowledged impact of climate change on mental health. Bulletin of the Atomic Scientists, 72, 292-297. doi:10.1080/00963402.2016.1216505

Graham, P., \& Arshad-Ayaz, A. (2016). Learned unsustainability: Bandura's bobo doll revisited. Journal of Education for Sustainable Development, 10, 262-273.

Heidegger, M. (1971). Poetry, language, thought. New York, NY: Harper \& Row.

Heidegger, M. (1977). The question concerning technology and other essays. New York, NY: Harper \& Row. 
Hird, M. (2017). Waste, environmental politics and dis/engaged publics. Theory, Culture \& Society, 34(2-3), 187-209.

Hutchins, E. (1995). Cognition in the wild. Cambridge, MA: MIT Press.

Ingold, T. (2007). Lines: A brief history. London, UK: Routledge.

Ingold, T. (2013). Making: Anthropology, archaeology, art and architecture. London, UK: Routledge.

Knappett, C. (2004). The affordances of things: A post-Gibsonian perspective on the relationality of mind and matter. In E. DeMarrais, C. Gosden, \& C. Renfrew (Eds.), Rethinking materiality: The engagement of mind with the material world (pp. 43-52). Cambridge, UK: McDonald Institute Monographs.

Latour, B. (2017). Europe as refuge. In H. Geiselberger (Ed.), The great regression (pp. 78-87). Cambridge, UK: Polity.

Lave, J., \& Wenger, E. (1991). Situated learning: Legitimate peripheral participation. Cambridge, UK: Cambridge University Press.

Malafouris, L. (2013). How things shape the mind: A theory of material engagement. Cambridge, MA: MIT Press.

Malafouris (2015) Metaplasticity and the primacy of material engagement. Time and Mind, 8,351-371. doi:10.1080/1751696X.2015.1111564

Merleau-Ponty, M. (1962). Phenomenology of perception. New York, NY: Routledge.

Miller, D. (Ed.) (2005). Materiality. Durham, NC: Duke University Press.

Miller, D. (2008). The Comfort of Things. Cambridge, UK: Polity.

Miller, D. (2010). Stuff. Cambridge, UK: Polity.

Renfrew, C. (2001). Symbol before concept: Material engagement and the early development of society. In I. Hodder (Ed.), Archaeological theory today (pp. 122-140). Cambridge, UK: Polity.

Renfrew, C. (2009). Prehistory: The making of the human mind. New York, NY: Modern Library.

Robbins, P. (2007). Lawn people: How grasses, weeds, and chemicals make us who we are. Philadelphia, PA: Temple University Press.

Smith, M. (2011). Ethics, biopolitics, and saving the natural world. Minneapolis: University of Minnesota Press.

Stefanovich, I. L. (2001). Safeguarding our common future: Rethinking sustainable development. Albany, NY: SUNY Press.

Tilley, C. (1991). Material culture and text: The art of ambiguity. London, UK: Routledge.

Tilley, C. (1994). A phenomenology of landscape: Places, paths, and monuments. Oxford, UK: Berg.

Tilley, C. (1999). Metaphor and material culture. Oxford, UK: Blackwell.

Turkle, S. (2011). Alone together: Why we expect more from technology and less from each other. New York, NY: Basic Books.

Väliahho, P. (2014). Biopolitical screens: Image, power, and the neoliberal brain. Cambridge, MA: MIT Press.

Vygotsky, L. V. (1978). Mind in society. Cambridge, MA: Harvard University Press.

Vygotsky, L. V. (1986). Thought and language. Cambridge, MA: MIT Press.

Wertsch, J. V. (1991). Voices of the mind: A sociocultural approach to mediated action. Cambridge, MA: Harvard University Press.

Wertsch, J. V. (1998). Mind as action. Cambridge, MA: Oxford, UK: Oxford University Press. 